\title{
STUDY ON RELATIVE ABUNDANCE AND DISTRIBUTION OF TIGER PREY BASE (UNGULATES) IN KHATA CORRIDOR, BARDIA NATIONAL PARK
}

\author{
Shalu Adhikari*, Ambika Khadka \\ Department of Environmental Science and Engineering, School of Science, Kathmandu \\ University, P.O. BOX NO. 6250, Kathmandu, NEPAL \\ *Correspondence author: shalu@ku.edu.np
}

Received 10 December, 2008; Revised 15 January, 2009

\begin{abstract}
The study provides information on distribution, abundance of wild ungulates and their link to habitat characteristics at a landscape level conservation. Khata Corridor is an important component of Terai Arc Landscape. It is about $9 \mathrm{~km}$ long and connects Bardia National Park, Nepal with Katarniaghat Wildlife Sanctuary, India. Relative abundance and distribution of Tiger prey base species (wild ungulates) was studied from mid April to mid June 2008 at Khata Corridor. A total of 127 transects (1 transect $=625 \mathrm{~m}$, distance between adjacent transect $=100 \mathrm{~m}$, distance between two parallel transect $=100 \mathrm{~m}$ ) containing 2700 circular plots of $10 \mathrm{~m}^{2}$ were laid and sampled following Smith et al (1999). A total of 2043 wild ungulates pellets were counted within the sampled area with a mean pellet group abundance of 0.75 pellets per plot. Mean pellet group abundance of Spotted deer, Wild boar, Monkey, Hog deer, Barking deer and Blue bull were 0.63, 0.06, 0.05, 0.02, 0.00 and 0.00 per plot respectively. Species wise ungulate abundance showed that Barking deer was highest in Low Density Mixed Forest, Spotted deer in Grassland, Hog deer in both Grassland and Low Density Mixed Forest, Blue bull only in Low Density Mixed Forest, Monkey in Riverine Forest and Wooded Grassland, and Wild boar in Wooded Grassland. Distribution pattern of wild ungulate species was of Clumped type $\left(S^{2} / a=93.10\right)$. Out of four habitat types, flood plains with riverine forest and grasslands were considered important habitats. Khata has been experiencing different levels of degradation also has tremendous conservation potential to ensure long term viability of large mammals (eg. Tigers) if restored and integrated into landscape level conservation plans.
\end{abstract}

Keywords: Corridor, Ungulates, distribution, abundance, habitats, degradation.

\section{INTRODUCTION}

Royal Bengal Tiger (Panthera tigris tigris), one of the world's most magnificent mammal, is highly endangered and faces extinction in the near future if present trends of poaching and habitat degradation continues (DNPWC/MoFSC/GoN 2007). Conservation of tiger is regarded as the conservation of the whole ecosystem as the endangered species' position is at the apex of the food chain. It is an indicator species of a healthy ecosystem. Fragmentation and loss of its natural habitat has made the tiger critically endangered (WWF 2002), in addition massive depletion of its prey species and poaching.

Therefore, tiger is in Appendix I of CITES (Convention on International Trade in Endangered Species of Wild Fauna and Flora) and Appendix I of Red Book of IUCN. In Nepal, the species is listed as protected under National Parks and Wildlife Conservation Act 1973 (DNPWC/MoFSC/GoN 2007). In 2001, His Majesty's Government of Nepal 
(HMG/N), with support from World Wildlife Fund (WWF), initiated the Terai Arc Landscape Conservation Project (TAL), a revolutionary step to restore the ecological integrity of the Central Himalayan lowland forest landscape. The TAL encompasses a landscape mosaic of about 49,500 sq.km. extending from Bagmati River in eastern Nepal to Yamuna River in western India. TAL aims to linking the region's 11 parks and reserves into a network of protected areas through a well established framework that integrates programs in adaptive management and participation by communities and other stakeholders.

A primary objective of TAL is to restore the ecological integrity of the Terai forests that consequently increases the prey base in these forests. Tigers' prey can be divided into three categories viz small sized such as Barking Deer (Muntiacus muntjak), Four Horned Antelope (Tetracerus quadricornis) and Langur (Semnopithecus entellus), Medium sized such as Spotted Deer (Axis axis), Hog Deer (Axis porcinus), Wild Boar (Sus scorfa), large sized such as Sambar Deer (Cervus duvauceli duvauceli), Blue Bull (Boselaphus tragocamelus) and sometimes domestic livestocks (Cow, Buffaloo and Goat) are also preyed upon in fringe habitats. Wild ungulates are important constituents of faunal assemblage.

Information on prey abundance in national and community forests of Nepal is very limited. Better understanding of prey distribution in relation to human activities will in turn facilitate development of management strategies. Understanding distribution, abundance of tiger prey base is fundamental to implementation of the Terai wide conservation plan that seeks to increase the land base supporting tigers as the most significant threat to tiger occurrence is the depletion of prey base. Currently, Khata Corridor between Bardia National Park of Nepal and Katarniyaghat Wildlife Reserve of India and Basanta Corridor between Suklaphanta Wildlife Reserve of Nepal and Dudhuwa National Park of India are the key focus of TAL Nepal to assure the objectives of this program.

\section{OBJECTIVES}

The main aim was to study the relative abundance and distribution of tiger prey base (ungulates) in Khata Corridor with following specific objectives:

a. To investigate the distribution pattern of prey base per habitat through estimating pellet density

b. To identify the relative abundance and habitat preference of prey ungulates

c. To assess the effects of human related activities on prey abundance

\section{MATERIALS AND METHODS}

\section{Study Area}

Khata Corridor is about $9 \mathrm{~km}$ long connecting Bardia National Park (BNP) of Nepal with Katarniaghat Wildlife Scantuary in India. Geographically, the area is located between $\mathrm{N} 28^{\circ} 27.342^{\prime}-\mathrm{E} 81^{\circ} 12.591^{\prime}$ and $\mathrm{N} 28^{\circ} 22.19^{\prime}-\mathrm{E} 81^{\circ} 13.605^{\prime}$ in the southwestern region of Nepal in Bardia district. The highest elevation is 361 towards the North and lowest elevation is $121 \mathrm{~m}$ towards the South.

The area constitutes Geruwa (east branch of Karnali) River and its floodplains in the southern part of BNP. It comprises of Grasslands and Riverine forests as an important 
habitat for Asian One horn Rhino, Bengal Tiger, Asian Elephants, Ungulates and other wildlife. It has also been identified as critical area for restoration in the year 2000.

Dalla, Naurangha, Bhajpur, Dandagaun, Patharbhoji, Manaughat and Khata are the nearest settlements to the Geruwa River. Tharu are indigenous community of the area and others are migrated from different areas like Pyuthan, Jumla, Mugu, Kalikot etc. Agriculture and livestock husbandry are basic components of livelihood of the people. Fuelwood collection, timber smuggling, grass cutting, overgrazing, fishing, hunting and snaring, sand and stone quarrying are the major human activities in the area.

The study was conducted within the stretch of Geruwa and Karnali River and their riparian area within Khata and Kothiyaghat.

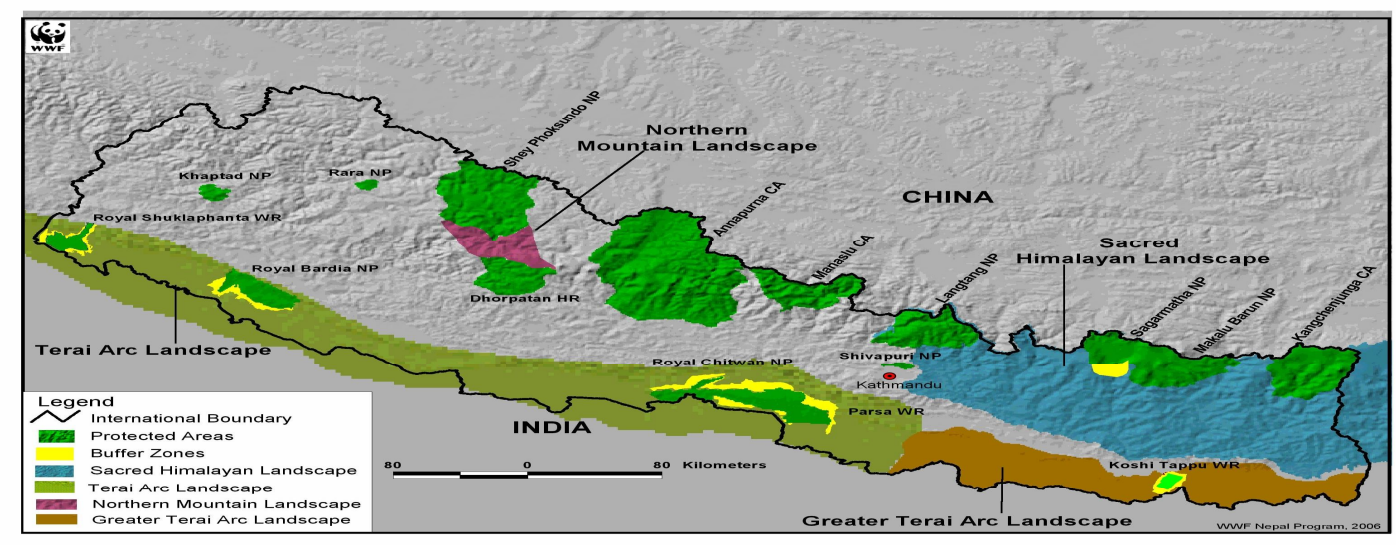

Picture 1: Terai Arc Landscape; Source: WWF Nepal

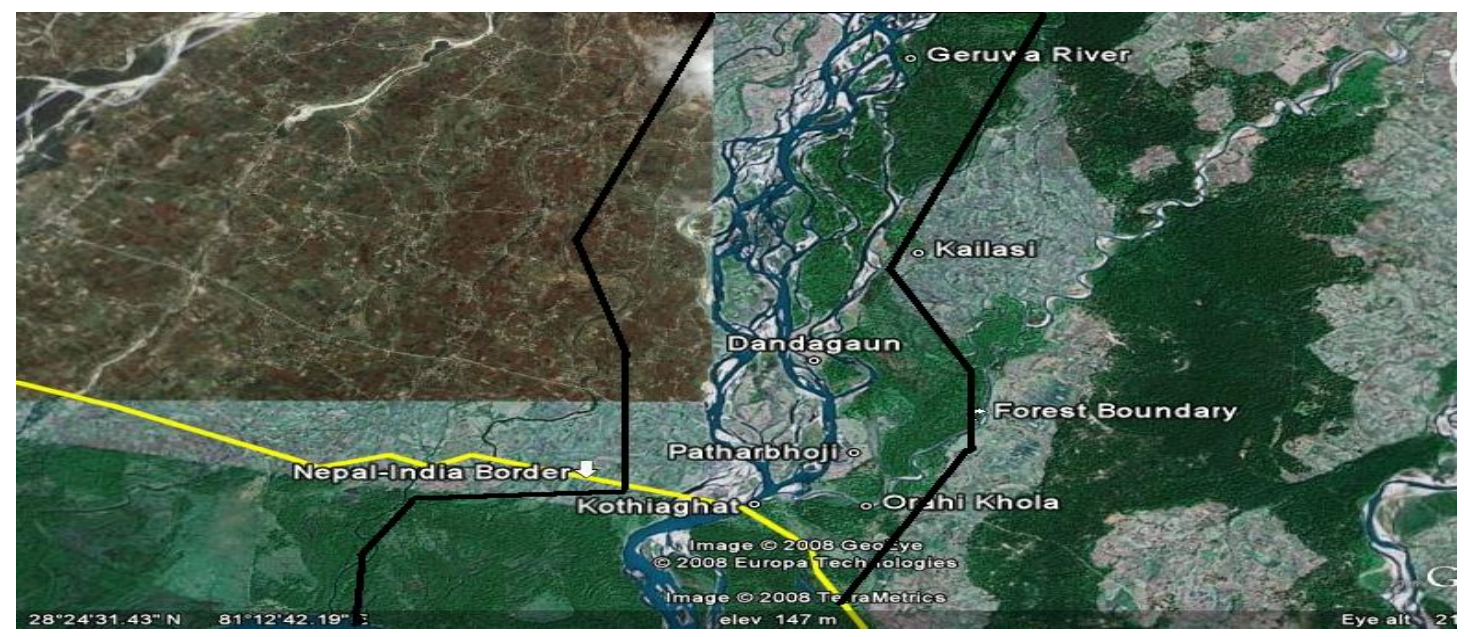

Picture 2: Satellite Image (Study area-Khata Corridor); Source: Googleearth (Jan09) 


\section{Sampling design}

Relative abundance and distribution of tiger prey species (wild ungulates) and domestic livestock was determined by counting pellet groups and dropping within $10 \mathrm{~m}^{2}$ circular plots placed at $25 \mathrm{~m}$ intervals along $625 \mathrm{~m}$ transect. (The starting points of each transects will be geo referenced for future use). Distance between two consecutive transect was kept at 100m; while distance between two parallel transect was kept at $100 \mathrm{~m}$. First starting point of transect was kept random and following transects were placed as per the above configuration. A total of 127 transects containing 2700 circular plots (27000sqm) were laid and sampled following Smith et al (1999). The orientation of transect was laid in east-west direction.

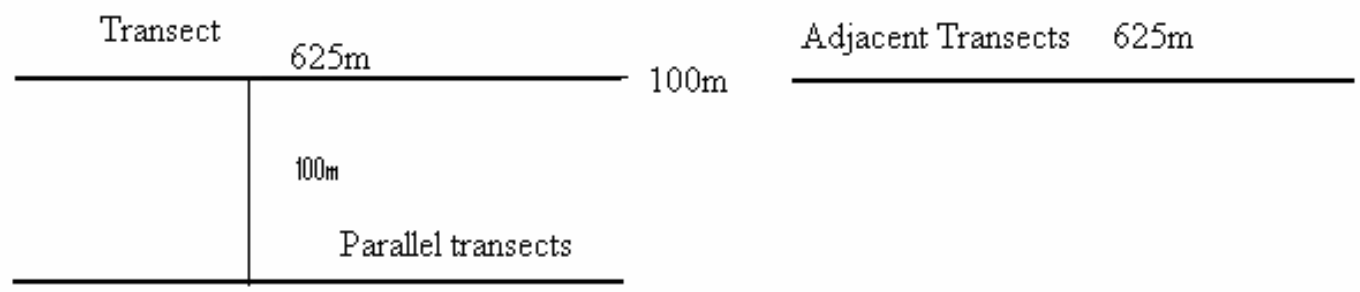

Figure a: Layout of Transects in the field

Pellets based on its size can be classified as follows.

\begin{tabular}{|l|l|l|}
\hline Small Prey Class & Medium Prey Class & Large Prey Class \\
\hline $\begin{array}{l}\text { Barking Deer, Four } \\
\text { Horned Antelope }\end{array}$ & $\begin{array}{l}\text { Spotted Deer, Hog } \\
\text { Deer }\end{array}$ & $\begin{array}{l}\text { Sambar, Swamp } \\
\text { Deer, Blue Bull }\end{array}$ \\
\hline
\end{tabular}

The materials used in the study were
1. GPS (Garmin)
2. Silva Compass
3. Ranging Rod $(1.78 \mathrm{~m})$
4. Measuring tapes
5. Rope $(25 \mathrm{~m})$
6. Data Sheets

\section{Data Analysis}

Following calculations were done to analyze ungulates data.

Density: Density of pellet groups per plot was taken as an index for abundance in the study.

Density/ plot $=\underline{\text { Total number of pellets groups present in all studied plots }}$

Where 1 plot $=10 \mathrm{~m}^{2}$

$$
\text { Total plots studied }
$$

\section{Frequency:}

Frequency of species $=$ Total no. of plots in which species pellet is found Total no. of sampling plots studied

$$
\text { Relative frequency of species }(\%)=\frac{\text { Frequency of the species }}{\text { Total frequency of all species }} \times 100
$$


Distribution: Distribution pattern of ungulates among 107 transects was analyzed by calculating ratio of variance and mean $\left(\mathrm{s}^{2} / \mathrm{a}\right)$ as follows (Odum, 1996).

$\left(\mathrm{s}^{2} / \mathrm{a}\right)=1$ (random distribution)

$\left(\mathrm{s}^{2} / \mathrm{a}\right)<1$ (regular distribution)

$\left(\mathrm{s}^{2} / \mathrm{a}\right)>1$ (clumped distribution)

Where $\mathrm{s}^{2}=$ variance $=1 / \mathrm{n} \Sigma(\mathrm{x}-\mathrm{a})^{2}$

$\mathrm{x}=$ sample value; $\mathrm{a}=$ mean value

Chi- Square contingency test was used to find out significant differences in the distribution of ungulates in different studied samples.

Chi-Square $\left(\chi^{2}\right)=\Sigma \frac{(x-a)^{2}}{a}$

Where $\mathrm{x}=$ observed (or sample) value; $\mathrm{a}=$ expected value (or mean value)

Habitat preference: Habitat preference was calculated following (Pokhrel, 1996).

Habitat preference $(\mathrm{HP})=(\mathrm{PPE} / \mathrm{TPP}) \times 100$

Where,

PPE $=$ Pellet present in each habitat type

$\mathrm{TPP}=$ Total pellet present in all the habitat type

\section{Environmental variables used in analysis}

- Vegetation types

- Riverine Forest (RF)

- Low Density Mixed Forest (LM)

- Grassland (GS)

- Wooded Grassland (WG)

- Human disturbances index (number of cutting of trees and lopping of branches, disturbances range from 0-10)

\section{RESULTS AND DISCUSSION}

A total of 2043 wild ungulate pellets were counted within the sampled area of 27000sq. m. Species considered as wild ungulates were Barking Deer (Muntiacus muntjac), Spotted Deer (Axis axis) (referred as Chital in the study), Hog Deer (Axis porcinus), Blue Bull (Boselaphus tragocomelus) (referred as Nilgai in the study), Monkey (Presbytis entellus ) (referred as Langur in the study) and Wild boar (Sus scrofa).

A total of 136 elephant (Elephas maximus) dung, 106 rhino (Rhinoceros unicornis) dung, and 997 rabbit (Lepus nigricollis) pellets were also observed during the entire study in the sampling plots but were not included for study. A total of 81 animal tracks or signs were observed while 16 Chital, 4 Hog Deers, 8 Langurs, 1 Tiger and 1 Wild boar were directly sighted during the study on transects. However, Barking Deer was not directly observed but their barking was heard while studying along river bank of Karnali during evening. 


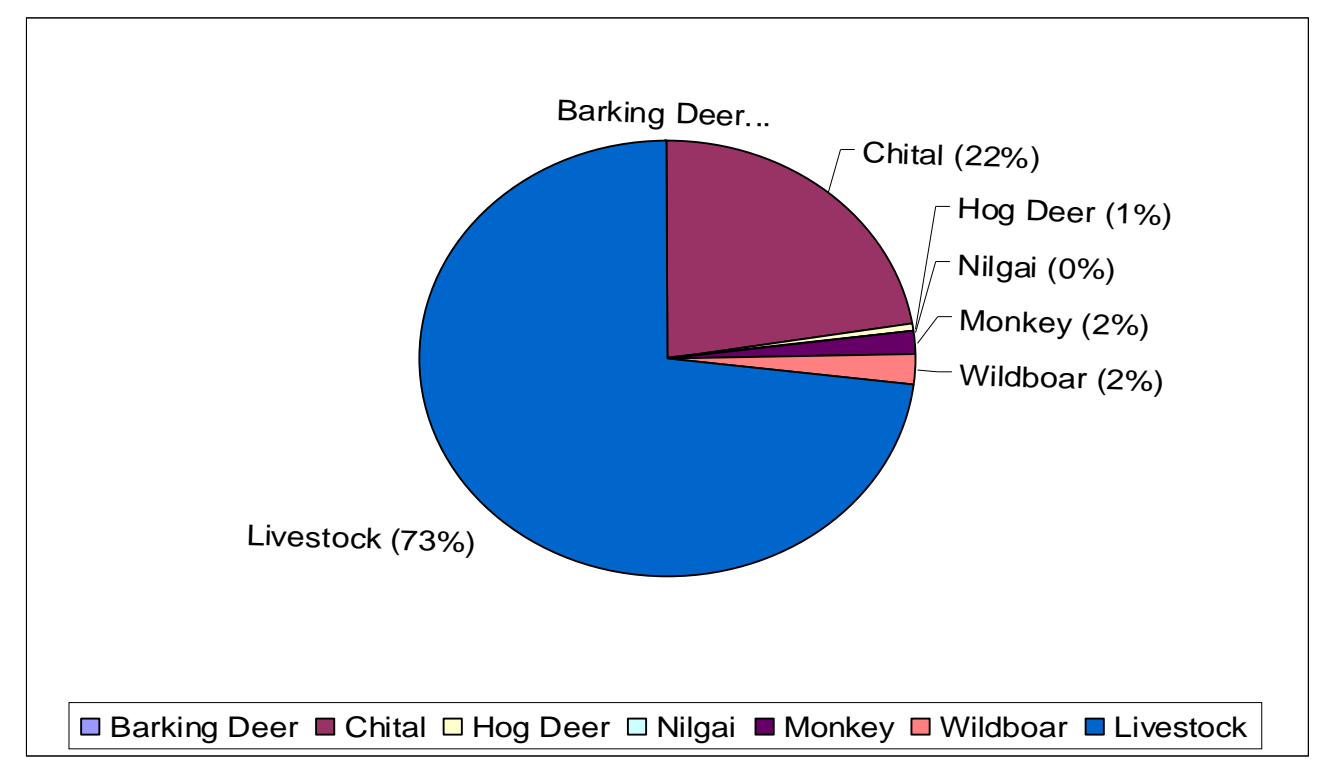

Figure 1: Ungulate and Livestock species composition in Khata Corridor

\section{Species wise Ungulate abundance}

\section{Barking Deer}

A total of 8 Barking Deer pellets were observed in the study sites. The highest mean pellet group abundance of 0.01 per plot (1 plot equal to $10 \mathrm{~m}^{2}$ ) was found in Low density mixed forest. The Barking Deer pellets were absent in Riverine Forest and Wooded Grassland while 6 pellet groups were found in Mixed Forest habitat, 1 pellet groups in Grassland and 1 pellet group in Wooded Grassland.

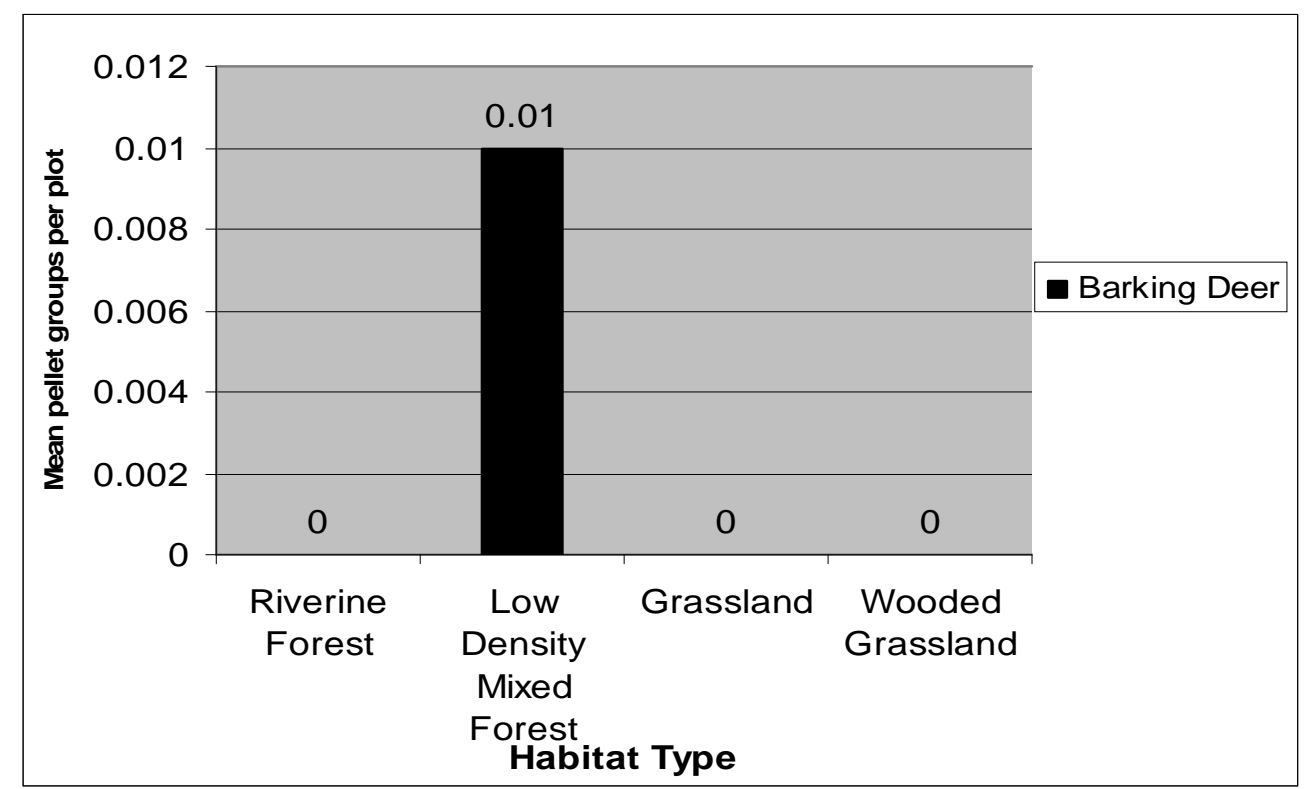

Figure 2: Mean pellet groups abundance of Barking Deer by habitat type 


\section{Chital}

The total number of pellet group of Chital was 1706 with the mean pellet abundance of 0.63 pellet groups per plot. The highest abundance was found in Grassland with 0.70 pellet groups per plot, followed by Wooded Grassland, Low Density Mixed Forest and Riverine Forest with $0.66,0.61$ and 0.53 respectively.

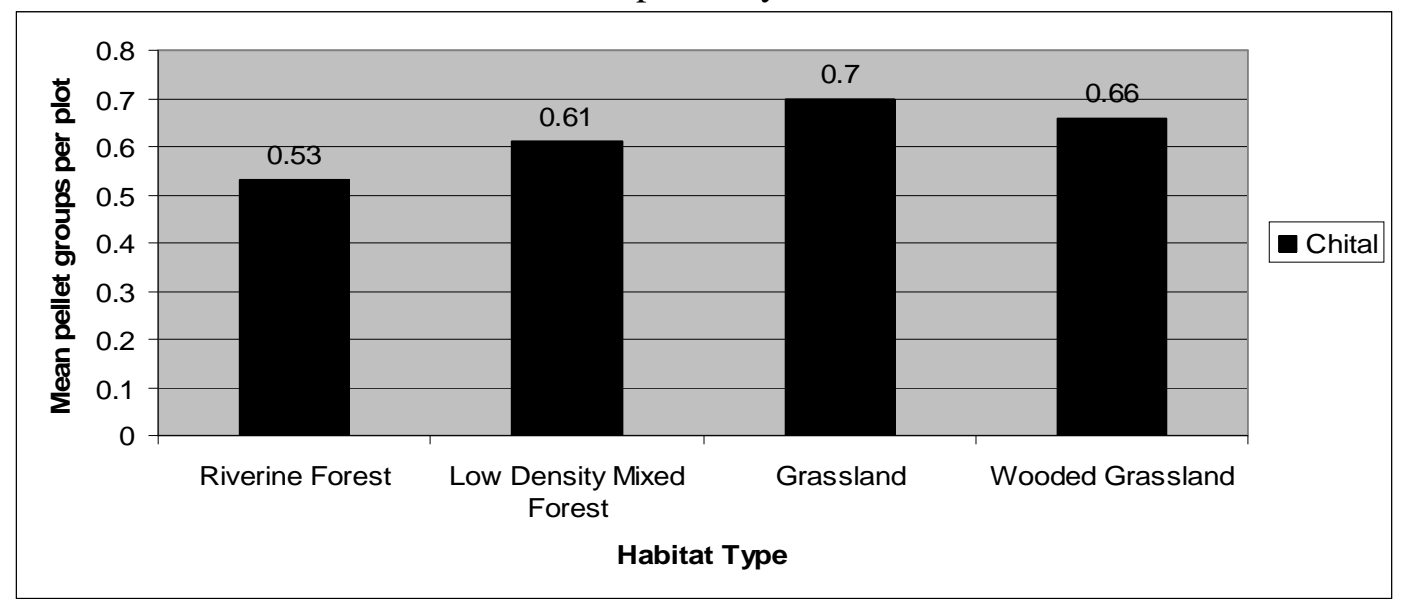

Figure 3: Mean pellet groups abundance of Chital by Habitat Type

\section{Hog Deer}

A total of 44 Hog Deer pellets were found with the mean pellet group abundance of 0.02 pellets per plot. The highest abundance of the species was found in Grasslands and Low Density Mixed Forest with 0.02 pellet groups per plot, followed by Riverine Forest and Wooded Grassland with 0.01 pellet groups per plot.

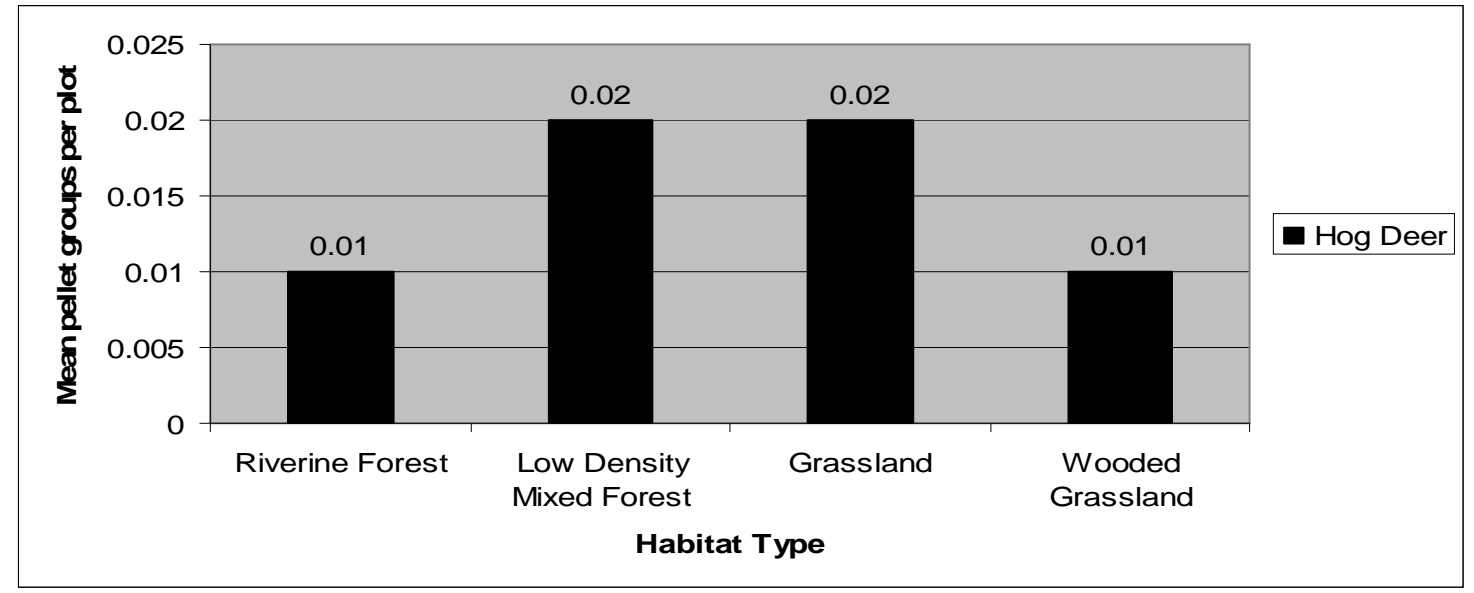

Figure 4: Mean pellet group abundance of Hog Deer by Habitat Type

\section{Nilgai (Blue Bull)}

A total of 6 Blue Bull pellet groups was found with the highest mean pellet group abundance of 0.01 in Low Density Mixed Forest habitat. The Blue Bull pellet groups were absent in Riverine Forest habitat, Grassland habitat and Wooded Grassland habitat. A total of 8 pellet groups were found only in Low Density Mixed Forest habitat. 


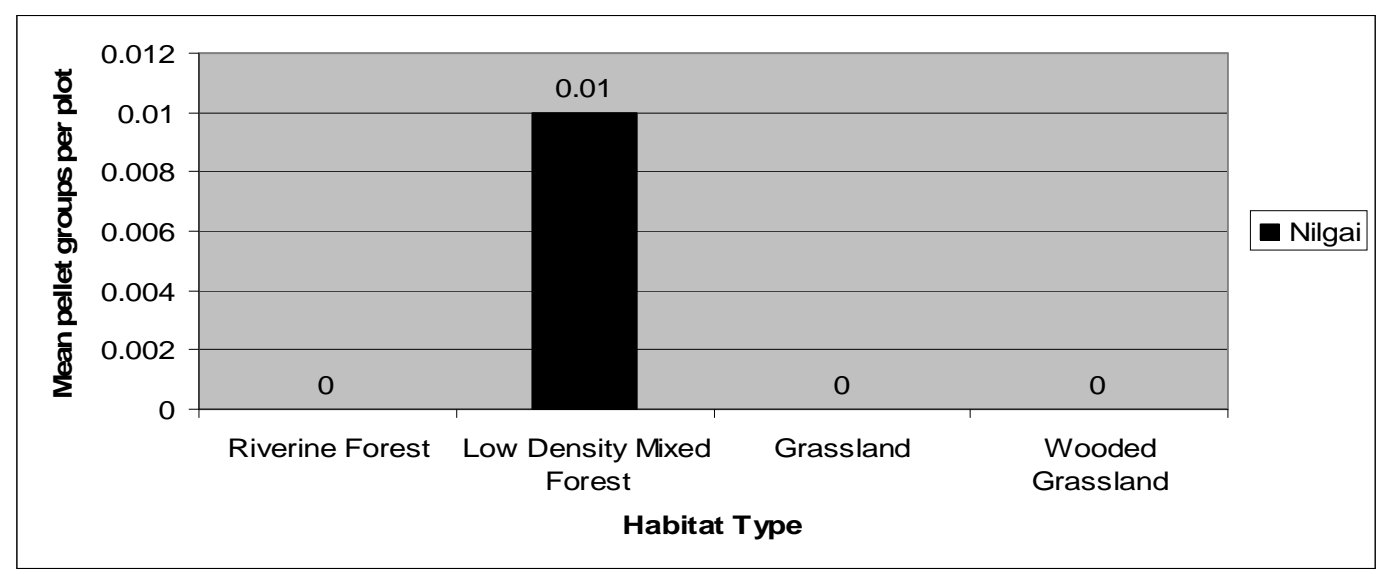

Figure 5: Mean pellet group abundance of Blue Bull (Nilgai) by Habitat Type

\section{Monkey (Langur)}

A total of 122 monkey pellet groups were found in the study site with the mean pellet group abundance of 0.05 pellet groups per plot. The highest pellet group abundance was found both in Riverine Forest and Wooded Grassland with mean pellet group abundance of 0.03 pellet groups per plot. This was followed by mean pellet group abundance of 0.02 per plot in Low Density Mixed Forest habitat and Grassland habitat.

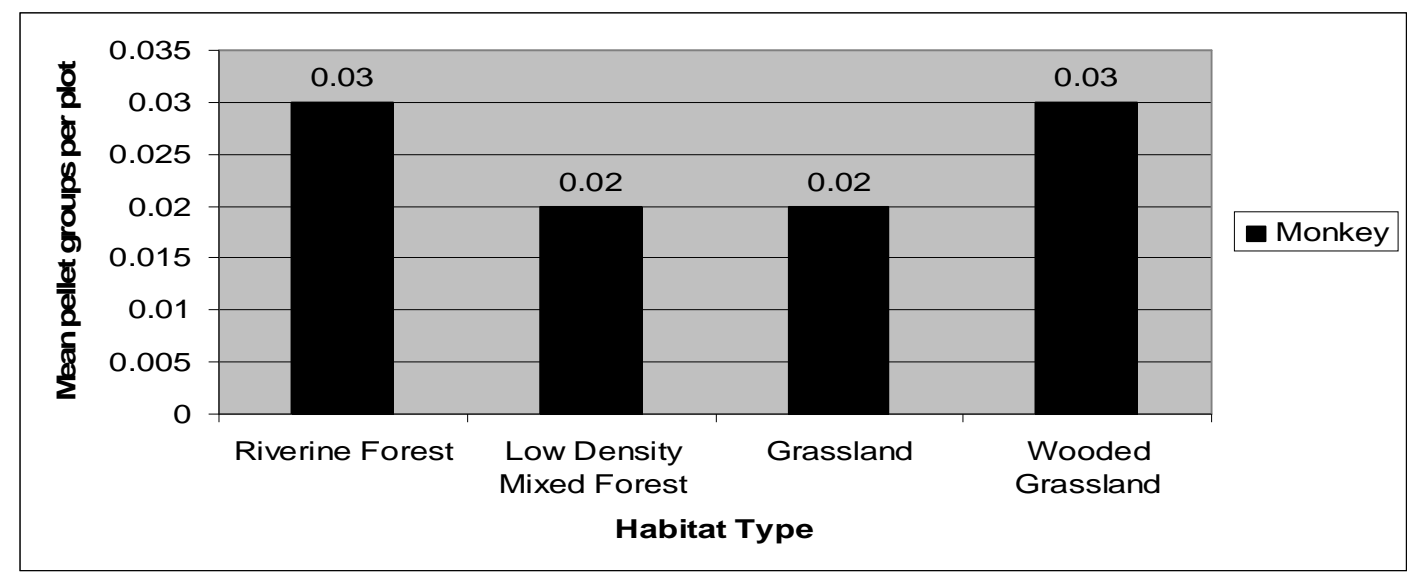

Figure 6: Mean pellet group abundance of Monkey by Habitat Type

\section{Wild Boar}

A total of 157 Wild boar pellet groups were found in study area with the mean pellet group abundance of 0.06 pellet groups per plot. The highest pellet group abundance was found in Wooded Grassland with mean abundance of 0.09 pellet groups per plot followed by Riverine Forest, Low Density Mixed Forest and Grassland, all with mean abundance of 0.05 pellet groups per plot. 


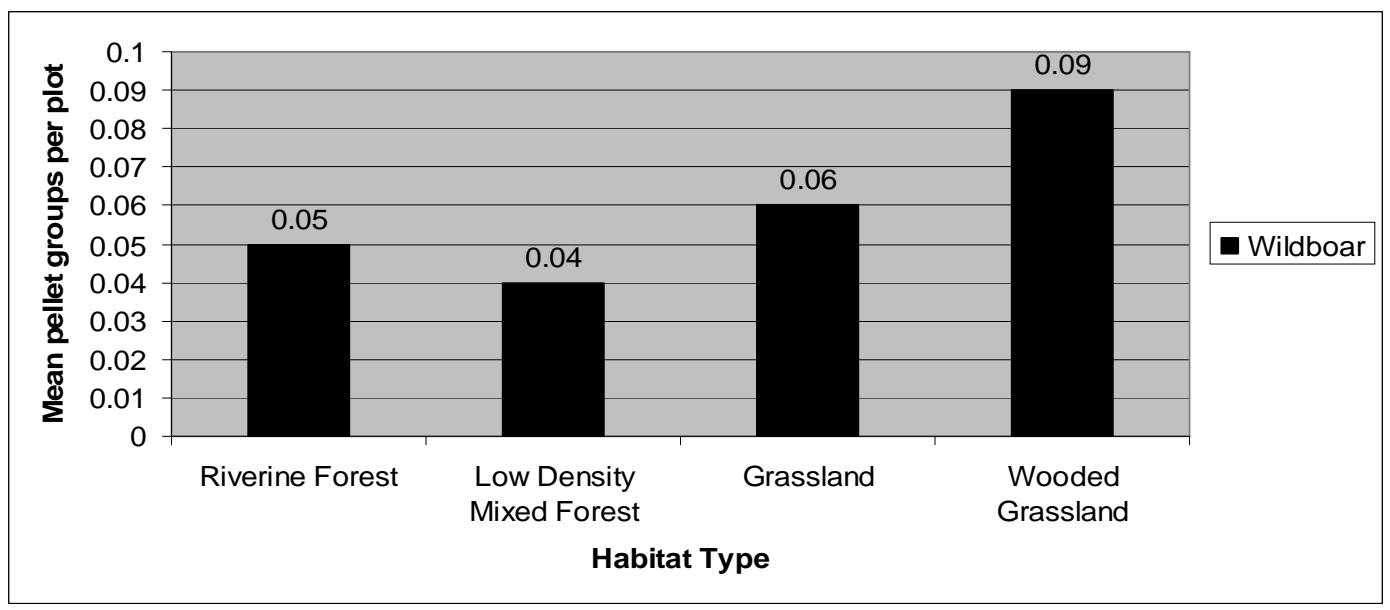

Figure 7: Mean pellet group abundance of Wild boar by Habitat Type

\section{Habitat wise Ungulates Pellet groups Abundance and Composition}

The highest mean pellet group abundance of Ungulates was found in Grassland with mean pellet group abundance of 0.81 pellet groups per plot followed by Wooded Grassland, Low Density Mixed Forest and Riverine Forest with mean pellet group abundance of $0.70,0.79,0.62$ pellet groups per plot respectively.

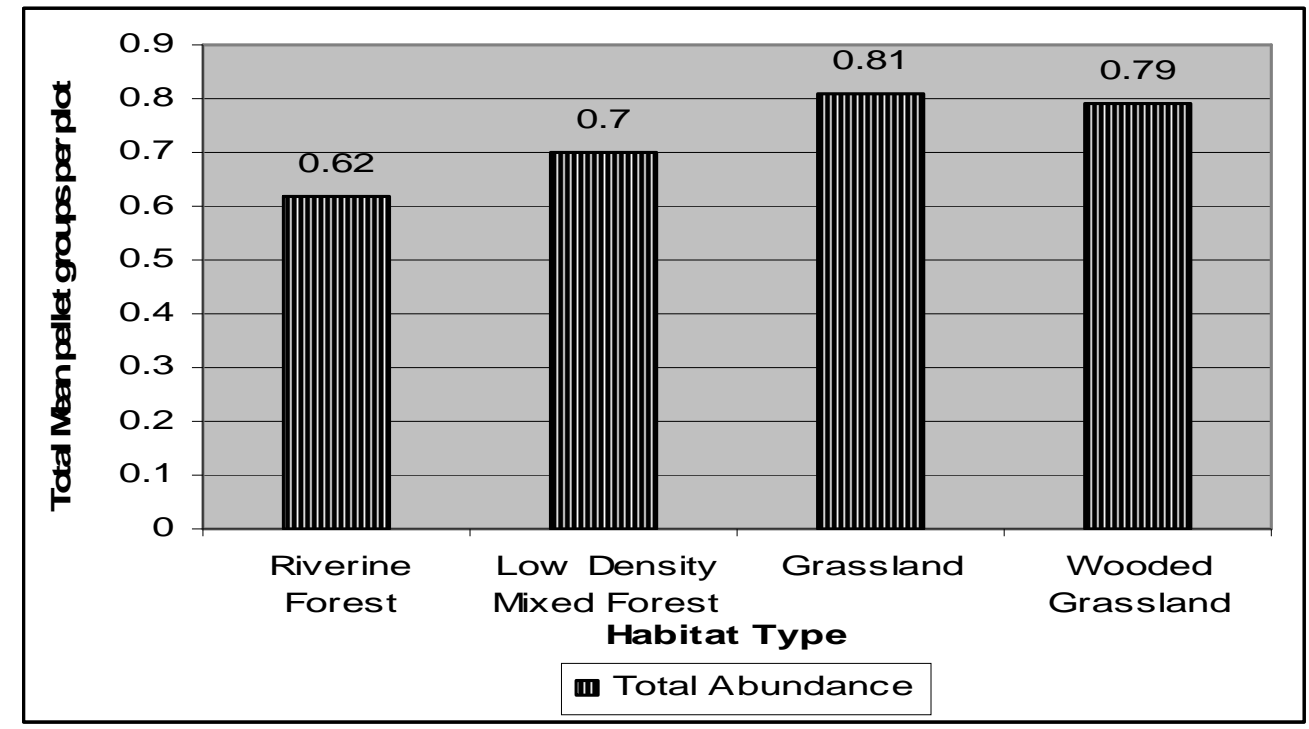

Figure 8: Habitat wise Total Mean pellet group abundance of Ungulates 


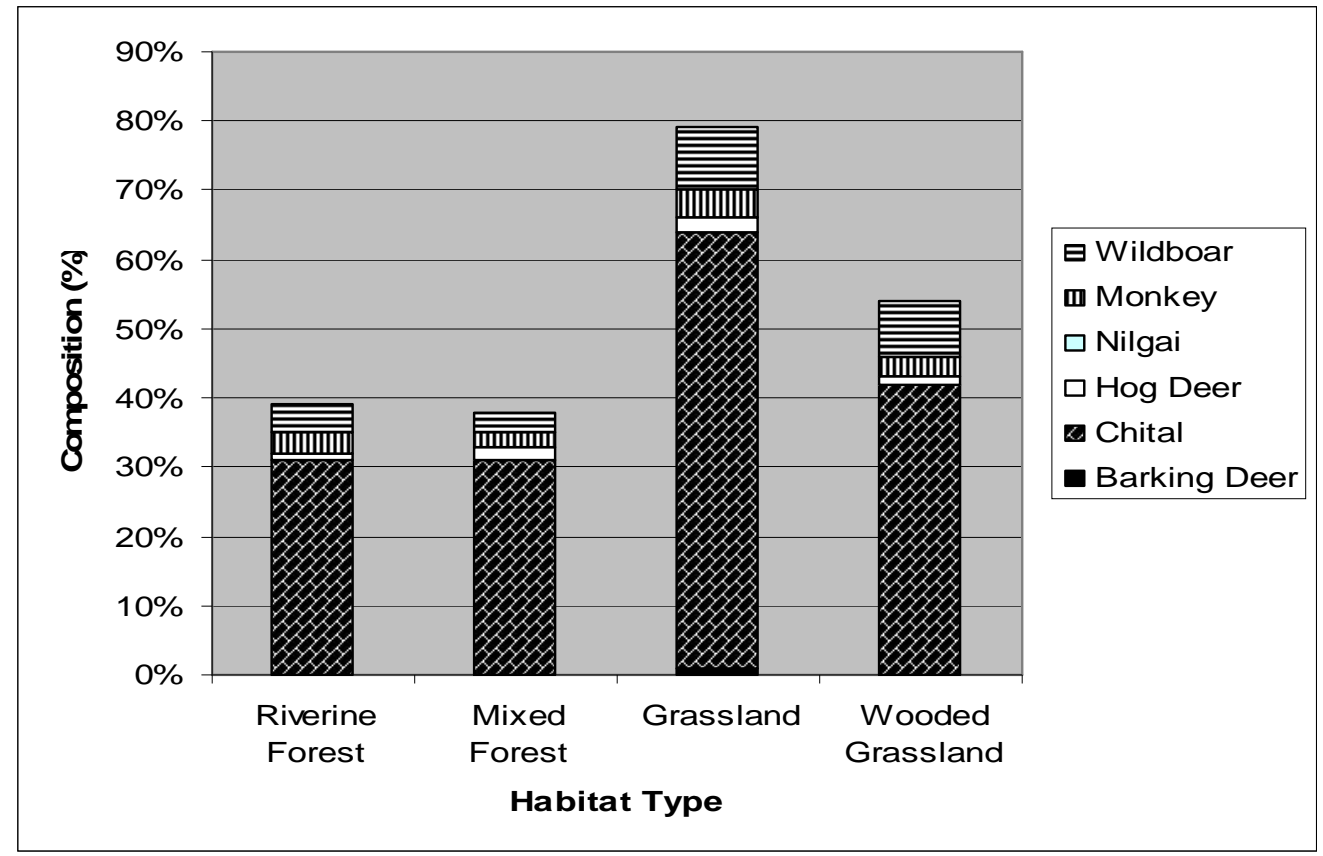

Figure 9: Habitat wise Composition of Wild Ungulates

\subsection{Frequency and Relative Frequency}

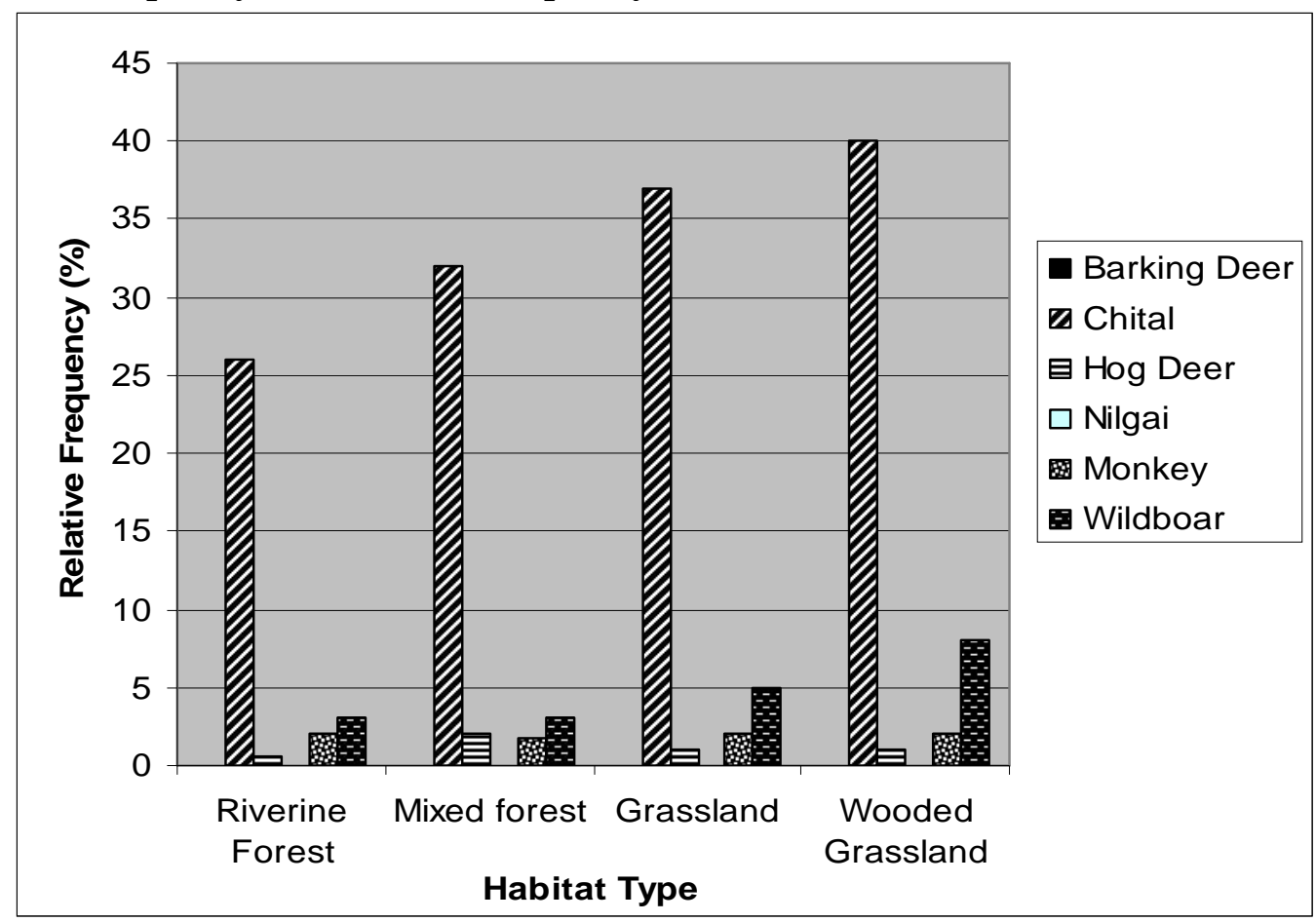

Figure 10: Relative frequencies of Wild Ungulate pellets in different habitats

Frequency analysis of the ungulate pellets showed Chital as the most frequent species in Riverine Forest with $26 \%$ relative frequency, it was followed by Wild Boar with $3 \%$ while others were negligible. The conditions were same for MF, GS and WG. This indicated that the probability of observing plots with pellets out of the total plots laid was highest with Chital in all habitat types. 


\section{Distribution Pattern}

The distribution patterns of Wild Ungulates species in 127 transects or samples in the study site were found to be of Clumped type $\left(\mathrm{S}^{2} / \mathrm{a}=93.10\right)$. The Chi-square contingency test showed that there was a significant difference between different samples studied and ungulates. Biological populations in natural habitat generally exhibit clumped type distribution pattern (Odum, 1996). This suggests that the ungulates are not distributed equally in all areas. The difference in occurrence of the ungulate pellets means that ungulate prefers different areas of the Corridor Forest and Floodplain differently, which indicate the difference in their preference for different habitats. This means that they do not utilize all the habitats equally and each habitat is not equally favorable to the ungulates.

Among the total samples studied for the Wild Ungulate pellets, 14 transects studied in Ganeshpur Sisinihya Community Forest recorded the highest number of pellet groups of 346. The second highest number of pellet groups were recorded in 12 transects studied in Shiva Buffer Zone area. This is followed by 10 transects studied in Sonaha Phanta, which recorded a total pellet groups of 188 .

\section{Mean pellet group abundance in different level of Human Disturbances}

Lesser the disturbances created by humans, greater was the abundance of prey and also good cover for Tiger for stalking prey. A mean pellet group of 0 was the abundance of ungulates and conversely, lesser the level of disturbances, greater was the livestock pellet groups abundance, indicating areas highly used by livestock rather than wild ungulates.

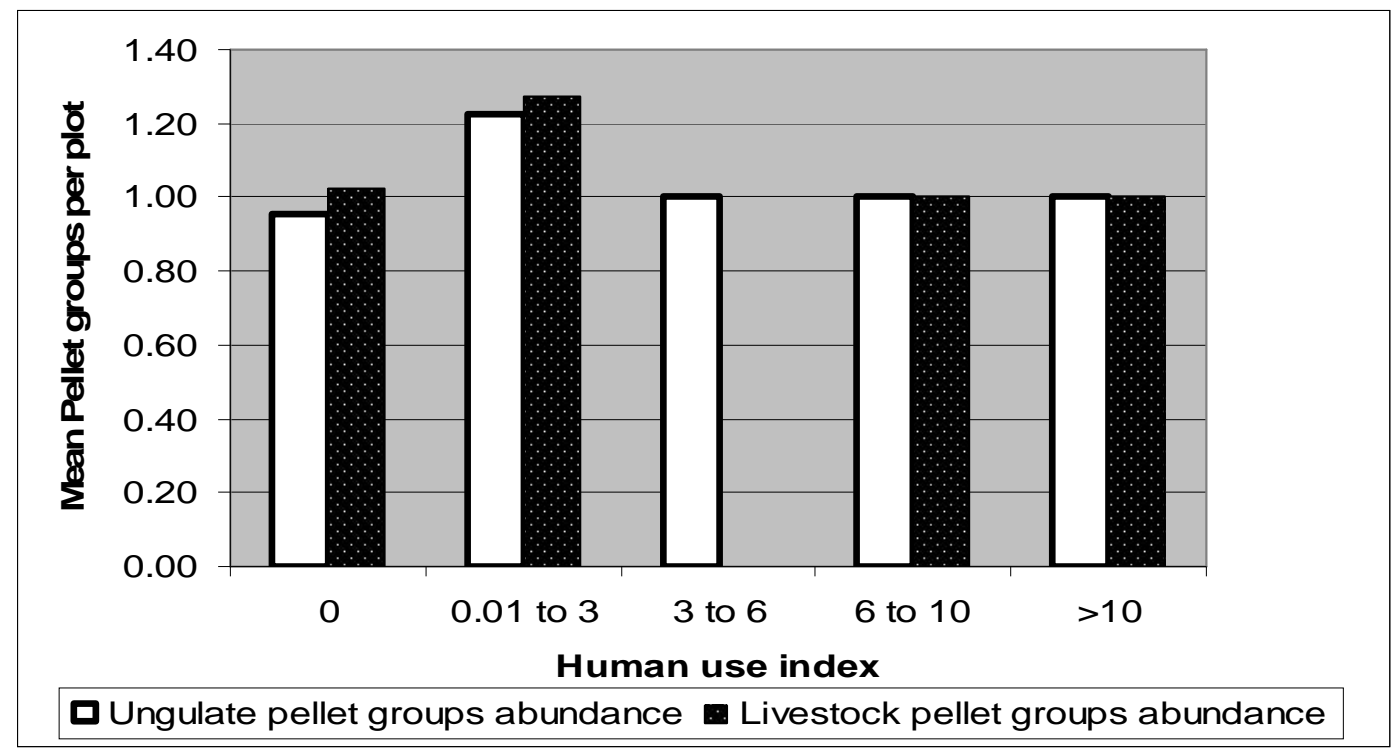

Figure 11: Mean pellet groups per plot Vs Human Use index

\section{Habitat Preference of Ungulates}

Barking Deers preferred Grassland habitat over Low Density Mixed Forest. Dinerstein (1987) hypothesized that the small rumen to body size ratio of Barking Deer and higher nutritional requirement restrict this animal to forested habitat where fruits, leaves, flowers, and buds are more abundant. Besides, its sedentary and shy nature along with anti-predator strategy of being inconspicuous makes it concentrate more in dense forest than in open and disturbed areas (cited in Thapa 2003). 
Likewise, Chital are generalist and thus prefer Grassland habitat the most, which was followed by Wooded Grassland. Chital prefer newly burned phantas as feeding habitats (Moe 1993, cited in Naess \& Andersen 1993) and rest during mid days in forest habitat. In this study, mean pellet group abundance of Chital was the highest and also the encounter rate was highest with 2.37 per $10 \mathrm{~km}$.

Hog Deer prefer grass- covered delta islands, or open phantasm. During the day, Hog Deer shelter in tall grass (Dhungel and O'Gara 1991, cited in Naess \& Andersen 1993). Hog Deers are usually inhabits grassland but are seldom seen in forest (Tamang, 1982 cited in Pokhrel 2005). Habitat composition of Hog Deer shows that $45 \%$ of the contribution was done by grassland habitat and $27 \%$ contribution was from low density mixed forest. Riverine forest and wooded grassland contributed $13 \%$ and $15 \%$ respectively.

Wild boar was the second most abundant species in the study area. Wooded grassland, forest and dense forest were preferred habitats for Wild Boar, and they build shelters of grass, reeds or brush (Mochi and Carter 1971, Prater 1980, cited in Naess \& Andersen 1993). It is specifically more frequent in the fragmented parts than in continuous forest (Thapa 2003). The diversity of food preference of Wild Boar must be a possible reason for their becoming adaptive to different habitat types. The distribution of blue bull was very restricted; this species was found only in the dry scrub forest while Monkeys prefer Riverine Forest as this species was also found in all habitat type.

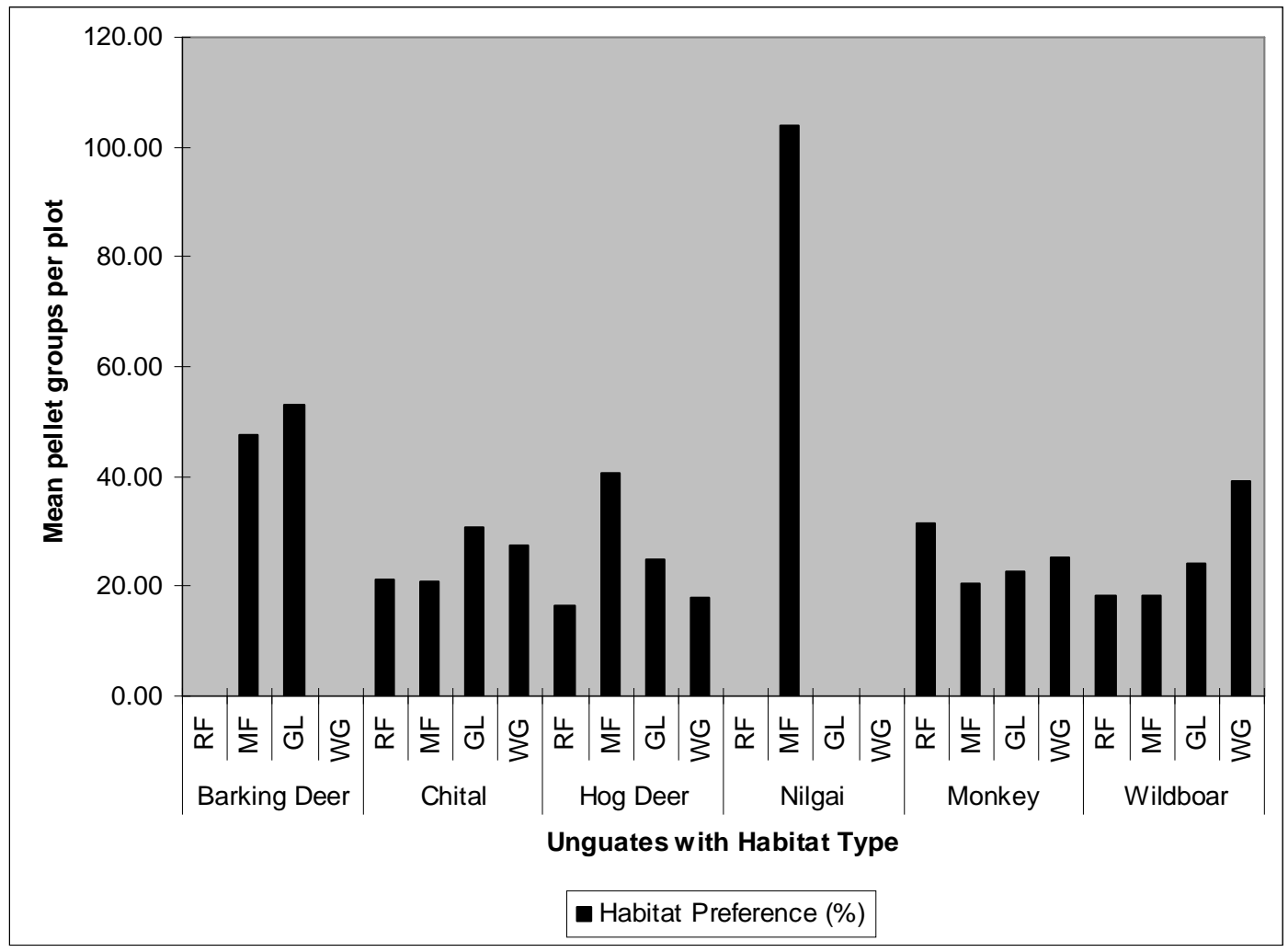

Figure 12: Habitat preference of Ungulates 


\section{Current threats}

Livestock grazing-One of the major threat for habitat degradation in Khata Corridor was abundant number of livestock being grazed in the area as it was evident with the presence of high number of livestock dung and pellet (5542 pellets) compared to 2043 of wild ungulates in transects studied.

a) Fuelwood/grass/ leaves/ niuro collection- Tharu women and children were seen frequently collecting leaves (pattya) and Niuro (Dryopteris cochleata). This was considered as a palatable and nutritious vegetable and was a famous word among the villager nearby. Human use index was evident from the fact that the tips of the plants were seen already plucked off.

b) Invasion of Alien Species-Lantana $s p$. was the only species which was dominant and widespread all over Khata Corridor. The biggest irony was that one part of riverine forest (next to Shiva $\mathrm{CF}$ ) was completely invaded by this species.

c) Tree felling/ Logging- Tree felling and logging was seen to be very common that all the big Khair and Sissoo trees were gone. The total number of cut trees observed while walking $67.5 \mathrm{~km}$. along transects were 248. People were busy cutting trees as it was heard that they were asked to prepare 1250 pole size wood for electric fencing. It was all Khair trees trees cut from the forest that led to detoration of habitat condition.

\section{CONCLUSIONS}

- High quality habitats i.e. Grassland and Riverine Forest support high ungulate biomass. So, they need to be managed properly.

- Distribution Pattern of ungulates species showed clumped type with highest pellet groups found in Ganeshpur Sisiniya Community Forest (CF) and Shiva CF. So, management must include habitat managements of these $\mathrm{CF}$ in order to support predators.

- Threats to these wild ungulates were their habitats used for livestock grazing and human encroachment to fulfill their basic need for fodder and fuelwood. So, these activities have to be addressed and management undertaken immediately for the overall management of Khata corridor.

\section{RECOMMENDATIONS}

1. This spatial layer, together with other spatial data layers (e.g. land use, human demographic structure, livestock population, local socio-economics, community forest distribution, point information on biodiversity) can serve as a powerful tool for developing a conservation strategy and planning site specific management across the landscape.

2. Periodical monitoring of these geo-referenced transects will help assess population changes in tiger prey species in future from management point of view.

3. This type of study should be continued in the years to come to compare the trends of the frequency, relative abundance and distribution, so that management plans could be formulated accordingly on a long- term basis.

\section{ACKNOWLEDGEMENTS}

This study would not have been possible without the assistance of many people directly and indirectly. We would like to thank WWF Nepal for the financial support to carry out the study. Thanks also go to Mr. Kanchan Thapa, Senior Research Officer, WWF Nepal for making all the logistic support during the stay at Khata and also arranging efficient 
field assistants. We would also like to thank Mr. Tikaram Tharu, Mr. Ramesh Tharu, Mr. Tirtharam Tharu, Mr. Lok Thary for their assistance during the field. Help from Krishna Pariyar, Mrs. Maya Yogi, Mr. Pannaram Tharu are highly acknowledged. Thanks also go to Miss Neha Shrestha and Mr. Narayan KC from WWF office Nepalgunj. Lastly, we would like to thank all the Khata people, villagers from Dalla, Dandagaun and Patharbhoji for their coordination during the field study.

\section{REFERENCES}

1. Dhungel, S.K., and O'Gara, B.W., 1991. Ecology of the Hog Deer in Royal Chitwan National Park, Nepal. Wildlife Monograph No. 119. Wildlife Society, Bethesda, MD.

2. Dinerstein. E., Rijal.A., Bookbinder, M., Kattel, B., and Rajuria, A. 1987. Tiger as neighbors; efforts to promote local guardianship of endangered species in lowland Nepal. Riding the Tiger. Cambridge University Press. 316pp.

3. DNPWC/MoFSC/GoN. 2007. Tiger Conservation Action Plan for Nepal, Kathmandu. 96pp.

4. Johnsingh, A.J.T., Ramesh, K., Qureshi, Q., David. A., Goyal, S.P., Rawat, G.S., Rajapandian, K., and Prased, S. 2004. Conservation Status of Tiger and Associated Species in the Terai Arc Landscape, India. Dehradun: Wildlife Institute of India. 110pp.

5. Karanth, K.U., and Nichols, J.D. (Eds), 2002. Monitoring of tigers and their preyA manual for Researchers, Managers and Conservationists in Tropical Asia.

6. Majupuria, T.C., and Majpuria, R. K., 1998. Resources and Management. Wildlife, National Parks and Reserves of Nepal.

7. Nagarkoti, A., and Thapa, T.B., 2007. Distribution Pattern and Habitat Preference of Barking Deer (Muntiacus muntjac) in Nagarjun Forest, Kathmandu. Himalayan Journal of Sciences, Volume 4, Issue 6.

8. Naesse, K. M., and Andersen, H.J., 1993. Assessing Census Techniques for Wild Ungulates in Royal Bardia National Park, Nepal. A thesis submitted to the Agricultural University of Norway in partial fulfillment of the requirements for the degree of Master of Science in Management and Conservation of Naturall Resources.

9. Odum, E.P. 1996. Third Edition, Fundamentals of Ecology, Natraj Publishers.

10. Pokharel, C.P., 1996. Food habit and habitat utilization of Swamp Deer (Cervus duvauceli duvauceli) in RBNP, Nepal. M.Sc. Dissertation, Tribhuvan University, Nepal.

11. Pokharel, S., 2005. Distribution and Abundance of wild ungulates in RSWR, Nepal. M.Sc. Dissertation, Tribhuvan University, Nepal.

12. Shrestha, M.K., 2004. Relative Ungulate Abundance in a Fragmented Landscape: Implications for Tiger Conservation. A thesis submitted to the faculty of the Graduate School of the University of Minnesota.

13. Shrestha, N.M., 2006. Study on the Frequency, Distribution and Relative abundance of Tiger Prey Base Species in the Karnali River Floodplains of Bardia National Park. A project report submitted in partial fulfillment of the Degree of Bachelors of Environmental Science (Hons.), Department of Environmental Sciences and Engineering, Kathmandu University.

14. Singh, P.B., 2007. Study the Faunal Diversity, Floral Diversity and determine current threats to the biodiversity of the Geruwa River at Khata Corridor. A thesis submitted in partial fulfillment of the requirement for the degree of Master of 
Environmental Science in Management and Conservation of Natural Resources to School of Environmental Sciences and Engineering, Kathmandu University.

15. Smith, D., 1999. Metapopulation Structure of Tigers in Nepal. Riding the Tiger: Tiger conservation in Human Dominated Landscape, Cambridge University Press, UK. 176-180pp.

16. Thapa, B., 2003. Habitat Heterogenity and Distribution of some Ungulates Prey Species in Barandabhar Forest Chitwan, Nepal. 